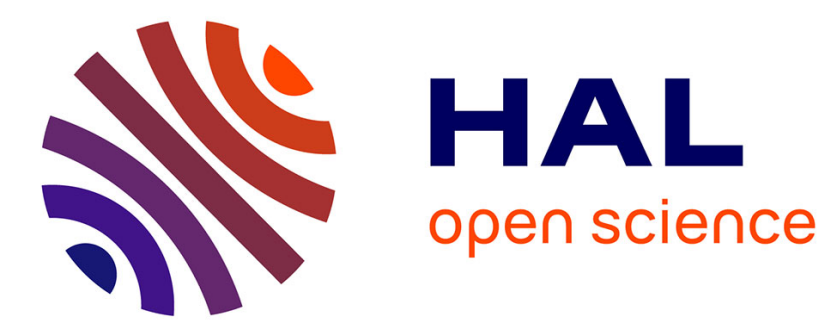

\title{
Reinforced macromolecular micelle-crosslinked hyaluronate gels induced by water/DMSO binary solvent
}

Hua Zhang, Penggang Ren, Hua Wei, Sami Halila, Amarachi Rosemary Osi, Yang Zhou, Zhong Dai, Rong Wang, Jing Chen

\section{- To cite this version:}

Hua Zhang, Penggang Ren, Hua Wei, Sami Halila, Amarachi Rosemary Osi, et al.. Reinforced macromolecular micelle-crosslinked hyaluronate gels induced by water/DMSO binary solvent. Soft Matter, 2020, 10.1039/d0sm01099e . hal-02948762

\section{HAL Id: hal-02948762 \\ https://hal.science/hal-02948762}

Submitted on 10 Nov 2020

HAL is a multi-disciplinary open access archive for the deposit and dissemination of scientific research documents, whether they are published or not. The documents may come from teaching and research institutions in France or abroad, or from public or private research centers.
L'archive ouverte pluridisciplinaire HAL, est destinée au dépôt et à la diffusion de documents scientifiques de niveau recherche, publiés ou non, émanant des établissements d'enseignement et de recherche français ou étrangers, des laboratoires publics ou privés. 


\title{
Reinforced macromolecular micelle-crosslinked hyaluronate gels induced by water/DMSO binary solvent
}

\author{
Hua Zhang ${ }^{a b}$, Penggang Ren $*^{a}$, Hua Wei ${ }^{b}$, Sami Halila ${ }^{c}$, Amarachi Rosemary \\ Osi ${ }^{b}$, Yang Zhou $*^{b}$, Zhong Dai ${ }^{a}$, Rong Wang ${ }^{b}$ and Jing Chen $*^{b}$ \\ ${ }^{a}$ School of Materials Science and Engineering, Xi'an University of Technology, Xi'an \\ 710048, China. E-mail: rengpg@126.com \\ ${ }^{b}$ Zhejiang Engineering Research Center for Biomedical Materials, Cixi Institute of \\ Biomedical Engineering, Ningbo Institute of Materials Technology and Engineering, \\ Chinese Academy of Sciences, Ningbo 315300, China. E- \\ mail: zhouyang876@nimte.ac.cn; jing.chen@nimte.ac.cn \\ 'Université Grenoble Alpes, Centre de Recherches sur les Macromolécules Végétales \\ (CERMAV, UPR-CNRS 5301), F-38000 Grenoble, France
}

Introducing macromolecular micelles into a biocompatible hyaluronic acid (HA) hydrogel is a promising strategy to improve its mechanical properties for biomedical applications. However, it is still unclear whether the solvent nature has an influence on the structure and property of HA gels especially when they are used for those cases containing binary solvents because reversible hydrophobic association within micelles could be weakened or even dissociated by organic solvents. In this work, we demonstrated that a binary solvent consisting of water and low-toxic dimethyl sulfoxide (DMSO), a commonly used cryoprotectant agent in biomedicine, can enhance the mechanical properties of hydrophobic-associated methacrylated hyaluronate (MeHA) gels crosslinked by diacrylated $\mathrm{PEO}_{99}-\mathrm{PPO}_{65}-\mathrm{PEO}_{99}$ (F127DA) macromolecular micelles, namely FH gels. The resulting FH hydro/organo-gels showed a crystalline structure due to polymer/solvent interactions. The FH gels showed a low swelling degree and the maximum strength (10.12 MPa), modulus (106.8 $\mathrm{kPa})$ and toughness $\left(1540 \mathrm{~J} \mathrm{~m}^{-2}\right)$ in DMSO with a volume fraction of around 0.6 . Moreover, the FH gels displayed a rapid recoverability under cyclic loading-unloading stress particularly in the presence of DMSO within the network due to 
their dual-dynamic dissipation networks. Such novel hydrophobic associated polysaccharide gels with tunable mechanical properties in binary solvents would be attractive in a cryopreservation system for cell-based applications.

\section{Introduction}

Hyaluronic acid (HA), a major component of the extracellular matrix (ECM) abundantly found in the cartilage, skin and eyes, functions as a backbone to recruit proteoglycans and glycoproteins into ECM structures and has a variety of applications in medicine including scaffolds for tissue engineering, dermatological fillers, and viscosupplementation for osteoarthritis treatment. ${ }^{1,2}$ Although high-molecular-weight HA at high concentration in physiological solution can form entangled molecular networks, the resulting viscoelastic HA solution does not have a long-lasting mechanical and shape integrity. HA hydrogels with covalent crosslinking networks have been extensively developed for clinical therapy instead of viscous HA solutions due to their shape retention. Yet commonly used HA hydrogels still suffered from low mechanical strength $(<400 \mathrm{kPa})$ and toughness $\left(<15 \mathrm{~kJ} \mathrm{~m}^{-3}\right)$, which severely handicaps their clinical applications. $\frac{3-5}{}$

To address the above issues, we recently developed a methacrylated hyaluronic acid (MeHA) hydrogel crosslinked by diacrylated $\mathrm{PEO}_{99}-\mathrm{PPO}_{65}-\mathrm{PEO}_{99}$ triblock copolymer

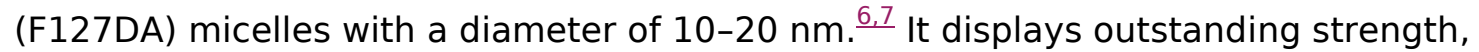
toughness and long-term network maintaining, which is attributed to the efficient energy dissipation through the hydrophobic association of PPO blocks in the core of micelles. Thanks to the excellent cytocompatibility and mechanical properties of such macromolecular micelle-crosslinked HA hydrogels, they are promising in extending their cell-based medical applications such as cell therapy, regenerative medicine, stem cell research, organ transplantation, etc. $\frac{7.8}{}$ For them, it is highly required that a sufficient number of cells with high activity and integrated bio-functionality can survive during the whole procedure. Currently, the cell cryopreservation system has become a routine strategy for the long-term storage of living cells because the biological activities of cells 
can be inhibited after cooling down to a low temperature, and the functions of the cells are also recovered after thawing at physiological temperature. To avoid the ice crystal damage into cells during the freezing-thawing process, a low content of cryoprotectant agent (CPA) is usually added in cell-culture medium for the cryopreservation system. For example, Zhao et al. developed a core-shell alginate hydrogel with very low concentration ( $2 \mathrm{~mol} \mathrm{~L}^{-1}$ ) of the cell membrane penetrating cryoprotective agent to achieve cryopreservation of stem cells. ${ }^{9}$ Popa et al. demonstrated that k-carrageenan hydrogels containing dimethyl sulphoxide (DMSO) as CPA can maintain cell viability and chondrogenic features after one-month cryopreservation in liquid nitrogen. ${ }^{10}$ DMSO has been the most applied CPA in the serum-supplemented culture medium. ${ }^{8,10-13}$ However, the hydrophobic association of F127DA micelles could be weakened or even dissociated by organic solvents, which brings an unexpected destruction of networks for those micelle-crosslinked hydrogels. $\stackrel{14-19}{2}$ Therefore, it is greatly required to engineer the mechanical properties of macromolecular micelle-crosslinked gels in a water/DMSO binary solvent based on a full understanding of the influence of solvent nature on the micelles and gel network.

In the continuous challenge to develop HA gels containing a binary water/DMSO solvent without compromising the mechanical properties, we systematically investigated the effect of solvent properties on the structure/property of F127 micelle-crosslinked HA (FH) gels. The FH gels were prepared by photoinitiated free radical copolymerization of diacrylate-terminated F127 (F127DA) micelles and MeHA in water. The corresponding aerogels were obtained by lyophilization and then were immersed in binary mixtures of DMSO/ $\mathrm{H}_{2} \mathrm{O}$ with different composition ratios, yielding hydro/organo-gels with an equilibrium swelling (Scheme $1 \mathrm{a}-\mathrm{d}$ ). The resulting $\mathrm{FH}$ gels formed a crystalline structure and exhibited a low swelling ratio, reinforced mechanical properties and fatigueresistance. This work provides a solvent-induced method to manipulate the microstructures of hydrophobic associated polysaccharide gels crosslinked by macromolecular micelles and enhance their mechanical properties for potential applications in the cell cryopreservation system. 
(a)

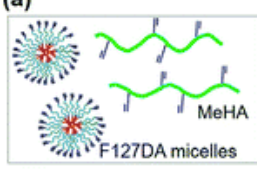

(d) FH hydro/organo-gel

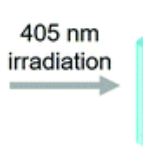

(b) FH hydrogel
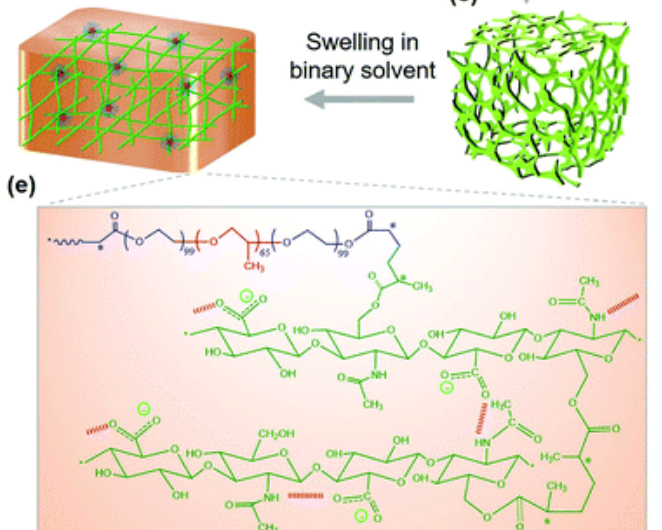

Scheme 1 Schematic illustrations for the preparation of F127DA crosslinked hyaluronate (FH) gel with DMSO/ $\mathrm{H}_{2} \mathrm{O}$ binary solvent. (a) The diagrams of hydrophobic associated F127DA micelles and methacrylate hyaluronate (MeHA) chains. (b and c) The networks of the FH hydrogel, freeze-dried FH aerogel and FH hydro/organo-gel. (e) The chemical structures of the FH gel.

\section{Materials and methods}

\subsection{Materials}

Pluronic F127 ( PEO $_{99}-\mathrm{PPO}_{65}-\mathrm{PEO}_{99}$ ), sodium hyaluronate $(50-70 \mathrm{kDa}$ ), molecular sieves (3 $\AA$ ), acryloyl chloride, methacrylic anhydride, triethylamine, toluene, dichloromethane, diethyl ether and anhydrous dimethyl sulfoxide were purchased from Sigma-Aldrich (Shanghai, China). Pluronic F127 was dried by azeotropic distillation with toluene before use. All solvents were dried with molecular sieves before use. Lithium phenyl-2,4,6trimethylbenzoylphosphinate (LAP) was bought from Tokyo Chemical Industry Co., Ltd, Japan. Pluronic F127 diacrylate (F127DA) and methacrylated hyaluronic acid (MeHA) used in this work were prepared based on the previously reported methods. $\frac{6,7}{\text { Deionized water }}$ with a resistivity of $18.2 \mathrm{M} \Omega \mathrm{cm}$ prepared using an ELGA LabWater system (France) was used for all experiments.

\subsection{Preparation of gels}

In a typical preparation, F127DA and MeHA were dissolved in deionized water to prepare a homogeneous solution with a concentration of $10 \mathrm{wt} \%$ and $1 \mathrm{wt} \%$, respectively. LAP as the photoinitiator was subsequently added into the solution with a concentration of 0.1 wt\%. The mixture was degassed and then injected in a home-made mold using a 1.50 $\mathrm{mm}$ thick silicone rubber spacer sandwiched by two pieces of glass. The free radical polymerization was initiated by blue-light irradiation $\left(\lambda=405 \mathrm{~nm}, 10 \mathrm{~mW} \mathrm{~cm}^{-2}\right)$ for 2 min. The obtained micelle-crosslinked gels $(\mathrm{FH})$ were freeze-dried for $72 \mathrm{~h}$. To prepare gels with a mixed solvent containing DMSO and $\mathrm{H}_{2} \mathrm{O}$, the dried gels aforementioned were further immersed in binary DMSO/ $\mathrm{H}_{2} \mathrm{O}$ solvents with different compositions for 7 days until an equilibrium is achieved. The volume fraction ( $f$ ) of DMSO in the binary solvent was $0,0.2,0.4,0.6,0.8$ and 1 . Specifically, when $f=1$ or $f=0$, the gel contains only DMSO or water within the network, respectively. The corresponding gels are noted as $\mathrm{FH}_{f}$.

\subsection{Characterization}


Nuclear magnetic resonance (NMR) analysis. The obtained MeHA and F127DA were analysed by ${ }^{1} \mathrm{H}$ NMR on a Bruker Advance III spectrometer using $\mathrm{D}_{2} \mathrm{O}$ and deuterated chloroform as the solvent, respectively. The degree of modification of the MeHA was determined from the relative integrations of the methacrylate (HA 6.1 and $5.6 \mathrm{ppm}$ ) to the HA backbone protons. The acrylation degree of F127DA was calculated by using the ratio of the integrated area of the acryl protons of F127DA $(\delta=5.8-6.4)$ and the methyl protons in poly (propylene oxide) groups $(\delta=1.1)$.

Transmission electron microscopy (TEM). A drop of the F127DA suspension was cast on carbon-coated copper grids and dried at $37^{\circ} \mathrm{C}$ for TEM imaging (Tecnai F20, FEI Inc., Oregon) with an accelerating voltage of $200 \mathrm{kV}$.

Dynamic light scattering (DLS). DLS measurements on F127DA micelles in DMSO/ $\mathrm{H}_{2} \mathrm{O}$ solvents with different DMSO volume fractions were conducted using Zetasizer Nano ZS (Malvern, UK). The solutions in the quartz cuvette were equilibrated at $25^{\circ} \mathrm{C}$ for $120 \mathrm{~s}$ before tests. Four samples were tested to calculate the average and standard deviation values.

Rheological characterization. The gelation kinetics of FH hydrogels were assessed on a TA DHR-3 Rheometer with dynamic oscillatory time sweeps using a $20 \mathrm{~mm}$ measuring plate with a quartz plate connected to a blue light source. The FH precursors were photopolymerized by irradiation at a wavelength of $405 \mathrm{~nm}$ and an intensity of $10 \mathrm{~mW}$ $\mathrm{cm}^{-2}$. The blue-light was turned on at $100 \mathrm{~s}$ and remained on for another $480 \mathrm{~s}$.

Contact angle measurements. Contact angles were measured using a contact-angle meter (Dataphysics, OCA 15 plus) equipped with a CCD camera at ambient temperature. The volume of the binary solution droplet was approximately $20 \mu \mathrm{L}$. The contact angle was obtained by averaging the measured values of right and left positions for each droplet. Measurements were taken over 10 areas for each sample to calculate the average and standard deviation values.

Swelling behavior. The swelling degree of gels was assessed by the volume change $\left(V_{c}\right)$ and weight change $\left(W_{c}\right)$ of a cylinder sample before and after swelling which were calculated using the equations as follows:

$$
\begin{gathered}
V_{\mathrm{c}}=V_{\mathrm{s}} / V_{\mathrm{d}} \\
W_{\mathrm{c}}=W_{\mathrm{s}} / W_{\mathrm{d}}
\end{gathered}
$$

where $V_{d}$ and $W_{d}$ refer to the volume and weight of the dry sample, and $V_{s}$ and $W_{s}$ refer to the volume and weight of the swollen sample.

Wide-angle X-ray diffraction. Wide-angle X-ray diffraction (WAXD) measurements were carried out on a D8 Advance Davinci X-ray Powder Diffractometer (Bruker, Germany) at a

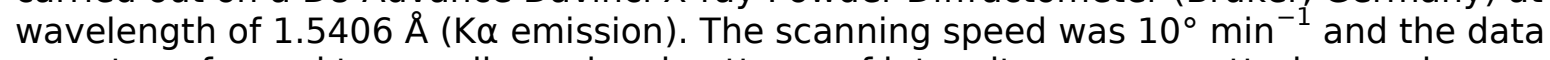
were transformed to one-dimensional patterns of intensity versus scattering angle.

Field emission scanning electron microscopy. Field emission scanning electron microscopy (FESEM, S4800, Hitachi, Japan) was performed to visualize the morphology of gels. The lyophilized specimens were freeze fractured in liquid nitrogen for observing the crosssectional morphology. The fracture surface was sputtered with gold at $8.0 \mathrm{kV}$.

Compression testing. Cylindrical gel samples were subjected to the compression testing by using a universal testing machine (Instron 5965, Instron Inc., USA) equipped with a 1

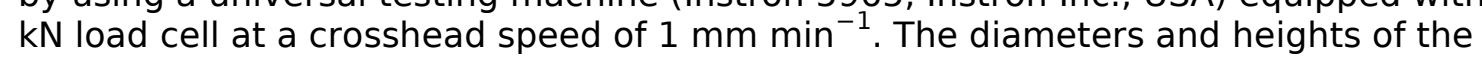
cylindrical swollen gel samples were obtained using a Vernier caliper. The modulus $(E)$ was determined by the slope of the stress-strain curve at low strain $(<25 \%)$. The fracture energy $(\Gamma)$ is defined as:

$$
\Gamma=\frac{U_{\mathrm{f}}}{\pi r^{2}}
$$

where $U_{\mathrm{f}}$ is the area beneath the force-displacement curve, and $r$ is the original radius of the sample.

Cyclic compression tests with a maximum strain of $60 \%$ were conducted at a crosshead speed of $1 \mathrm{~mm} \mathrm{m^{-1 }}$ four times. The dissipated energy $(\Delta \Gamma)$ of each cycle is defined as: $\Delta \Gamma=\Gamma_{\text {loading }}-\Gamma_{\text {unloading }}$ 


\section{Results and discussion}

\subsection{Preparation of FH gels with binary DMSO/ $\mathrm{H}_{2} \mathrm{O}$ solvent and their swelling behaviors}

F127DA was synthesized by modifying the end hydroxyl groups of F127 with acryloyl chloride, with $\approx 90 \%$ substitution according to the ${ }^{1} \mathrm{H}$ NMR spectrum (Fig. Sla, ESI \pm ). Such a triblock copolymer can self-assemble into macromicelles in water with a hydrodynamic size of about $76 \mathrm{~nm}$ via intra-molecular hydrophobic PPO entanglement, as shown in the DLS measurements (Fig. S1b, ESIt). MeHA with about $46.9 \%$ of methacrylation was synthesized by coupling methacrylate groups with hydroxyls (Fig. S2, ESI \pm ). The mixed solution consisting of F127DA and MeHA rapidly forms gel ( $<25 \mathrm{~s}$ ) and reaches an equilibrium within $120 \mathrm{~s}$ under blue light irradiation according to the in situ rheology measurement (Fig. S3, ESI \pm ). Subsequently, the as-prepared hydrogels were freeze-dried and immersed in binary DMSO/ $\mathrm{H}_{2} \mathrm{O}$ solvents with different composition ratios to achieve a swelling equilibrium (Scheme $1 \mathrm{a}-\mathrm{d}$ ). $\mathrm{HA}$ can directly form strong $\mathrm{NH} \rightarrow-\mathrm{O}_{2} \mathrm{C}$ hydrogen bonding interactions among chains in DMSO replaced from the secondary structure of HA in water with water bridged $\left(\left(-\mathrm{NH} \cdots \mathrm{O}-(\mathrm{H})-\mathrm{H} \cdots-\mathrm{O}_{2} \mathrm{C}\right)\right)$ multiple hydrogen bonds in DMSO. ${ }^{2,20}$ As a result, the obtained network of geld is constructed by the hydrophobic association of F127 micelles, covalent bonds between MeHA and micelles and newly formed hydrogen bonds between MeHA chains (Scheme 1e). These dynamic micelles and hydrogen-bonding within the gels would serve as sacrificial units to dissipate energy, and the MeHA moieties would limit the network swelling in binary solvents.

The surface wettability of the dried scaffold plays a key role in absorbing the solvent. To investigate the wettability of gels toward DMSO and water, the contact angles of DMSO/ $\mathrm{H}_{2} \mathrm{O}$ solvents with different ratios on the surfaces of lyophilized $\mathrm{FH}$ samples were first measured. As shown in Fig. 1a, the droplets of $\mathrm{DMSO} / \mathrm{H}_{2} \mathrm{O}$ with various ratios spread over the surface of lyophilized FH samples, indicating a DMSO/ $\mathrm{H}_{2} \mathrm{O}$-philic nature of the gels. Upon increasing the volume fraction of DMSO in the mixed solvent, the contact angle increases from $\sim 21^{\circ}$ to the maximum of $\sim 46^{\circ}$. Further increasing the DMSO content induces a reduction of contact angle down to $32^{\circ}$. These results imply that the wettability of F127DA micelle-crosslinked hyaluronate scaffolds relies on the $\mathrm{DMSO} / \mathrm{H}_{2} \mathrm{O}$ ratio, which would affect the swelling behavior of the FH scaffolds. 

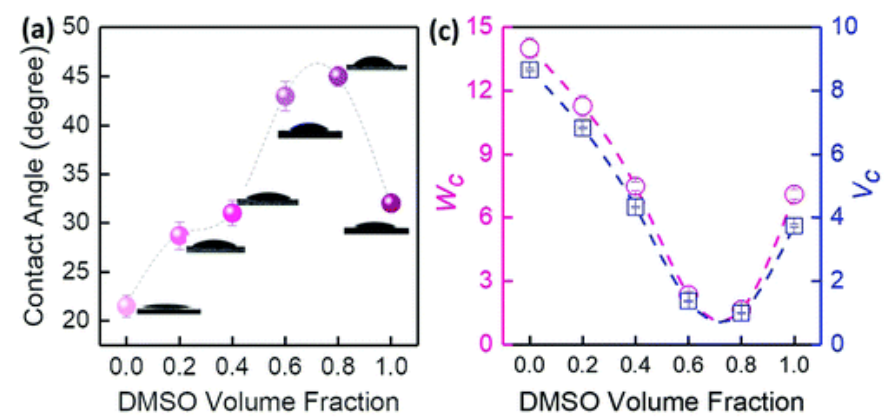

(b) $f \begin{array}{llllll}0 & 0.2 & 0.4 & 0.6 & 0.8 & 1.0\end{array}$

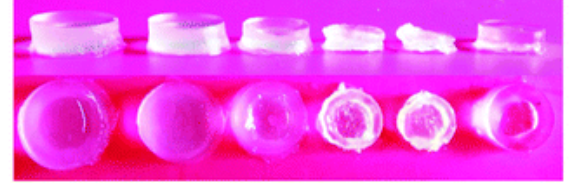

Fig. 1 (a) Effect of DMSO volume fraction on the surface wettability of FH scaffolds. (b) Digital photos of the swollen $\mathrm{FH}$ gels in DMSO/ $\mathrm{H}_{2} \mathrm{O}$ with different DMSO volume fractions. (c) Effect of DMSO volume fraction on the swelling behavior of FH gels including the weight changes $\left(W_{\mathrm{c}}\right)$ and volume changes $\left(V_{\mathrm{c}}\right)$.

The swelling behaviors of the FH scaffolds in DMSO/water binary solvent with various DMSO volume fractions are shown in Fig. $1 \mathrm{~b}$ and $\mathrm{c}$. As observed from the digital photos in Fig. 1b, the volume sizes of gels containing DMSO are obviously lower than that of the hydrogel $(f=0)$. The $\mathrm{FH}_{0}$ shows the maximum $W_{\mathrm{c}}$ and $V_{\mathrm{c}}$ of 14 and 8.7, respectively (Fig. 1c). As the DMSO fraction $(f)$ increases from 0.2 to 0.6 , the $W_{c}$ of $\mathrm{FH}$ gels significantly decreases from 11.3 to 2.4 . When $f$ is increased to 0.8 , the $\mathrm{FH}_{0.8}$ reaches the lowest swelling ratio of 1.7 . However, the organogel $\mathrm{FH}_{1.0}$ containing only DMSO $(f=1)$ is able to absorb DMSO with a high swell ratio of 7.1. This result indicates that the sizes of F127DA micelles in the $\mathrm{FH}_{1.0}$ gel would be much larger than those with binary solvents, which agrees with the DLS results of F127DA micelles with a larger size (173 $\mathrm{nm}$ ) in DMSO than that $(76 \mathrm{~nm})$ in water (Fig. S1b, ESI \pm ). The evolution of $V_{c}$ as a function of DMSO fraction in binary solvents follows similar behavior. The corresponding $V_{c}$ values are $6.8,4.3,1.4$, 1.1 and 3.7 with increasing $f$ from 0.2 to $0.4,0.6,0.8$ and 1.0 , respectively. Here, all FH gels show lower $W_{c}$ and $V_{c}$ than those of the $\mathrm{FH}_{0}$ hydrogel, indicating that the hydrogenbonding networks formed from DMSO-phobic HA chains limit the expansion of FH gels. ${ }^{2,20}$ On the other hand, the lowest swelling degree is observed for the gel containing $60-80 \%$ of DMSO, which is consistent with the maximum contact angle as mentioned above, suggesting that the DMSO- $\mathrm{H}_{2} \mathrm{O}$ interactions may play a crucial role in the $\mathrm{FH}$ gel swelling. According to previous studies, with decreasing $\mathrm{H}_{2} \mathrm{O}$ content in binary solvent, the strong hydrogen-bonding interaction between $\mathrm{H}_{2} \mathrm{O}$ and DMSO molecules causes the progressive dehydration of polymer ( $\underline{\text { Scheme } 1 b}) \cdot \underline{21-23}$ And the structure of the water 
cluster is broken down particularly when the molar fraction of DMSO is $\sim 0.35$ (the volume fraction of DMSO: $\sim 0.68) .{ }^{24-27}$ Such a dehydration process thus restricts the swelling of $\mathrm{FH}$ gels.

The state of polymer chains in solution is determined by the Flory-Huggins interactions $(\chi)$ between the polymer and the solvent based on the perspective of thermodynamics. The $\chi$ of $\mathrm{HA} / \mathrm{H}_{2} \mathrm{O}(0.439)$ is smaller than 0.5 , indicating a complete solubility of $\mathrm{HA}$ in water and the hydrated networks. $\frac{28,29}{2}$ For F127 chains, the calculated $\mathrm{PPO} / \mathrm{H}_{2} \mathrm{O}$ value is 3.48, much larger than that of the PPO/DMSO pair (0.55). ${ }^{30}$ Therefore, the PPO block drives the self-assembly of the copolymer chains into micelles in both solutions, while these micelles collapse much more in water. As a result, the $\mathrm{FH}_{0}$ hydrogel shows the maximum swelling degree (Fig. 1C). In binary solvents, the F127DA micelles show relatively small sizes around $60-70 \mathrm{~nm}$ from DLS measurements (Fig. S1b, ESII). The strong DMSO- $\mathrm{H}_{2} \mathrm{O}$ interactions and hydrogen-bonded $\mathrm{HA}$ chains synergistically contribute to the low swelling ratio of $\mathrm{FH}$ gels (Fig. 1C). In contrast, due to the weakened hydrophobic association of the PPO block in a good solvent (DMSO), the FH gel in only DMSO shows a large swelling ratio. Meanwhile, the hydrogen-bonded MeHA networks play a crucial role in limiting the network expansion.

\subsection{Microstructure evolution of $\mathrm{FH}$ gels with binary $\mathrm{DMSO} / \mathrm{H}_{2} \mathrm{O}$ solvent}

The swelling characteristics of FH gels reflect the structure evolution of these gels with different DMSO volume fractions. Such potential changes were in situ analyzed by WAXD. Generally, F127 usually has two prominent diffraction peaks located at $2 \theta=19.3^{\circ}$ and $23.4^{\circ}$, which are assigned to the (100) and (200) crystal planes. ${ }^{31-33}$ Alternatively, HA exhibits a broad characteristic peak at $2 \theta=\sim 20^{\circ}$ due to the crystallites. $\frac{34}{\text { However, the }}$ intensity of diffraction peaks for the $\mathrm{FH}_{0}$ hydrogel is hardly visible, indicating a full hydration status of MeHA chains and no dense stack of F127DA micelles (Fig. 2(a)). As seen, the increase of $f$ from 0.2 to 0.4 results in an obvious characteristic peak at $26.5^{\circ}$. This may reflect that the slight DMSO makes stronger intra/inter-molecular interactions between MeHA chains and MeHA-F127DA than those in hydrogels according to their smaller swelling characteristics. Furthermore, the diffraction intensities for $\mathrm{FH}_{0.6}, \mathrm{FH}_{0.8}$, and $\mathrm{FH}_{1.0}$ gels with a strong network shrinkage are obviously increased and the diffraction 
peak significantly shifted to $2 \theta=19.8^{\circ}$, which is mainly assigned to the crystalline structure in HA. These results indicate that DMSO-phobic MeHA facilitates the formation of crystallite structures due to the powerful hydrogen-bonding interactions between HA chains in binary solvent systems with relatively high DMSO content. Moreover, such structures are not changed in the $\mathrm{FH}_{1.0}$ gel with large swollen micelles.
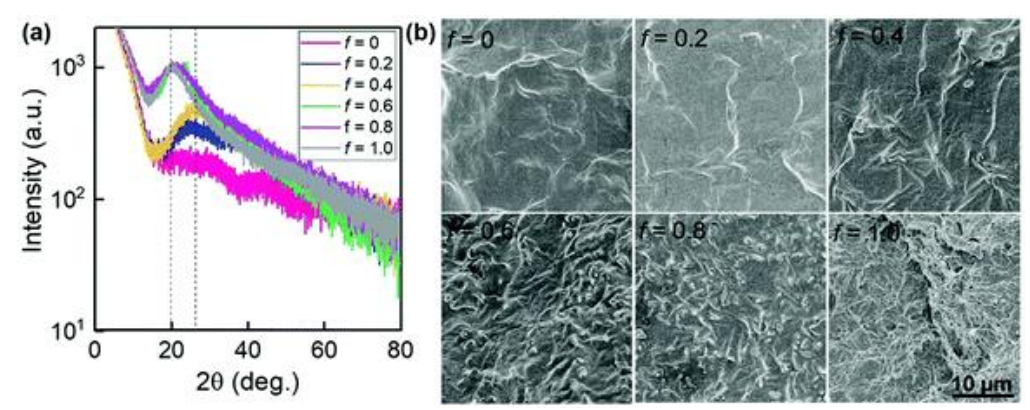

Fig. 2 (a) WAXD diffractions of FH gels containing DMSO/ $\mathrm{H}_{2} \mathrm{O}$ with different ratios. (b) The cross-sectional FESEM images of FH scaffolds treated with DMSO/ $\mathrm{H}_{2} \mathrm{O}$ solvent.

To visualize the morphologies in FH gels, the cross-sectional surfaces of dried gels were further observed by FESEM. As shown in Fig. 2b, the morphologies of FH gels are dependent on the DMSO contents. The $\mathrm{FH}_{0}$ hydrogel shows a relative smooth surface, while both $\mathrm{FH}_{0.2}$ and $\mathrm{FH}_{0.4}$ gels exhibit many ridges on their surfaces. As DMSO increased from 0.6 to 0.8 , the surfaces of gels became rougher accompanied by densely embedded micro-waves. Furthermore, the $\mathrm{FH}_{1.0}$ displays the roughest morphologies like large-scale flake stacks. These results corroborate the formation of crystallite phase structures with increasing DMSO in the polymer matrix.

\subsection{Mechanical properties of $\mathrm{FH}$ gels with binary $\mathrm{DMSO} / \mathrm{H}_{2} \mathrm{O}$ solvent}

The network structures of FH gels significantly influenced their mechanical properties. Fig. 4 shows their compressive properties. Due to the absence of hydrogen bonding, the $\mathrm{FH}_{0}$ hydrogel shows the minimum fracture strain $\left(\varepsilon_{\mathrm{f}}\right)$ of $70 \%$ and a fracture strength $\left(\sigma_{\mathrm{f}}\right)$ of $0.46 \mathrm{MPa}$ (Fig. $\left.3 \mathrm{a}\right)$. The corresponding $E_{25 \%}$ and $\Gamma$ are $\sim 39.5 \mathrm{kPa}$ and $144 \mathrm{~J}$ $\mathrm{m}^{-2}$ (Fig. 3b). The $\varepsilon_{\mathrm{f}}$ and $\sigma_{\mathrm{f}}$ of all FH hydro/organo-gels increase upon increasing the DMSO content in the DMSO/ $\mathrm{H}_{2} \mathrm{O}$ binary solvents (Fig. 3a). The maximum $\varepsilon_{\mathrm{f}}(\sim 90 \%)$ and $\sigma_{\mathrm{f}}(10.12 \mathrm{MPa})$ appear for the $\mathrm{FH}_{0.6}$ gels. The corresponding $\varepsilon_{\mathrm{f}}$ and $\sigma_{\mathrm{f}}$ values for $\mathrm{FH}_{0.2}$, $\mathrm{FH}_{0.4}$, and $\mathrm{FH}_{1.0}$ gels are about $80 \%$ and $0.84 \mathrm{MPa}, 85 \%$ and $1.45 \mathrm{MPa}$, and $83 \%$ and 3.15 $\mathrm{MPa}$, respectively. Similarly, the $E_{25 \%}$ and $\Gamma$ show a positive correlation with DMSO 
concentration, with the values of about $23.5 \mathrm{kPa}$ and $194 \mathrm{~J} \mathrm{~m}^{-2}$ for the $\mathrm{FH}_{0.2}$ gels, $68 \mathrm{kPa}$ and $320 \mathrm{~J} \mathrm{~m}^{-2}$ for the $\mathrm{FH}_{0.4}$ gels, and $106.8 \mathrm{kPa}$ and $1540 \mathrm{~J} \mathrm{~m}^{-2}$ for the $\mathrm{FH}_{0.6}$ gels, respectively (Fig. $3 \mathrm{~b}$ ). These results suggest that the original soft and weak $\mathrm{FH}_{0}$ hydrogel become a stiff and strong one. Moreover, due to the more formation of hydrogen bonds within gels and low solvent content, the $U_{\mathrm{f}}$ reaches the maximum in the $\mathrm{FH}_{0.6}$ gel. The $E_{25 \%}$ and $\Gamma$ of the $\mathrm{FH}_{1.0}$ gel decrease to about $69 \mathrm{kPa}$ and $830 \mathrm{~J} \mathrm{~m}^{-2}$, which is mainly attributes to the expanded F127DA micelles in the $\mathrm{FH}_{1.0}$ networks for the network deformation and energy dissipation. It is worth noting that both $\sigma_{f}$ and $U_{f}$ of the $\mathrm{FH}_{1.0}$ gel are much larger than those of the $\mathrm{FH}_{0.4}$ gel at almost the same $\varepsilon_{\mathrm{f}}(85 \%$ to $83 \%)$ and $E$ (68 $\mathrm{kPa}$ to $69 \mathrm{kPa}$ ). These results confirmed that the cooperation of hydrogen bonding interactions and F127DA micelle networks. As shown in Fig. 3c, the formed MeHA crystallite structures and the micelles within the gel can enable the occurrence of large deformations, dislocations and microcracks to resist compressive loading and dissipate energy.

(a)
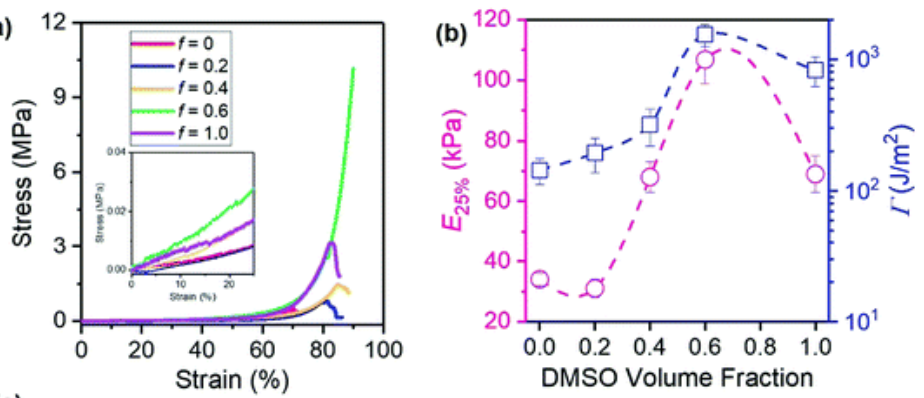

(c)

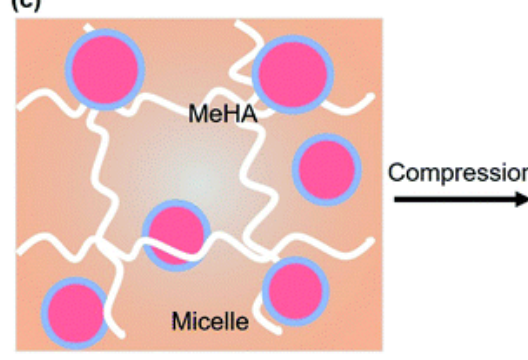

DMSO Volume Fraction
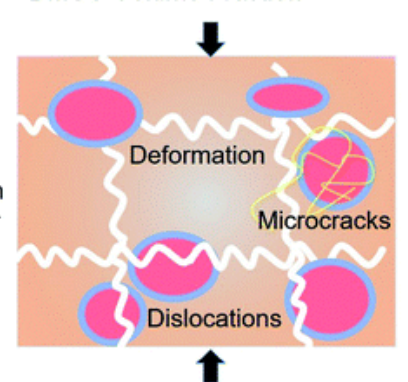

Fig. 3 (a) Compressive stress-strain curves of FH gels with different DMSO/ $\mathrm{H}_{2} \mathrm{O}$ ratios. The inset image represents the enlarged curves within $25 \%$ strain. (b) Effect of DMSO volume fraction on the modulus $(E)$ at a strain of $25 \%$ and fracture energy $(I)$ of FH gels. (c) Schematic diagram of the proposed mechanism for compressive FH gels.

The hysteresis and recovery of the gels were further evaluated by carrying out cyclical tests with a strain of up to $60 \%$. Typical hysteresis loops in the stress-strain curves are observed for each cycle (Fig. 4(a-e)). Fig. 4 f shows the hysteresis energy ( $\Delta \Gamma$ : the loop area) of $\mathrm{FH}$ gels after four consecutive loading/unloading cycles. The $\Delta \Gamma$ of the $\mathrm{FH}_{0}$ gel 
linearly decays after the first cycle, with the corresponding values decreasing from $6.2 \mathrm{~J}$ $\mathrm{m}^{-2}$ of the first cycle to $3.1 \mathrm{~J} \mathrm{~m}^{-2}$ of the fourth cycle, indicating the structural damages upon cyclic loadings and slow recovery with just water in the networks.
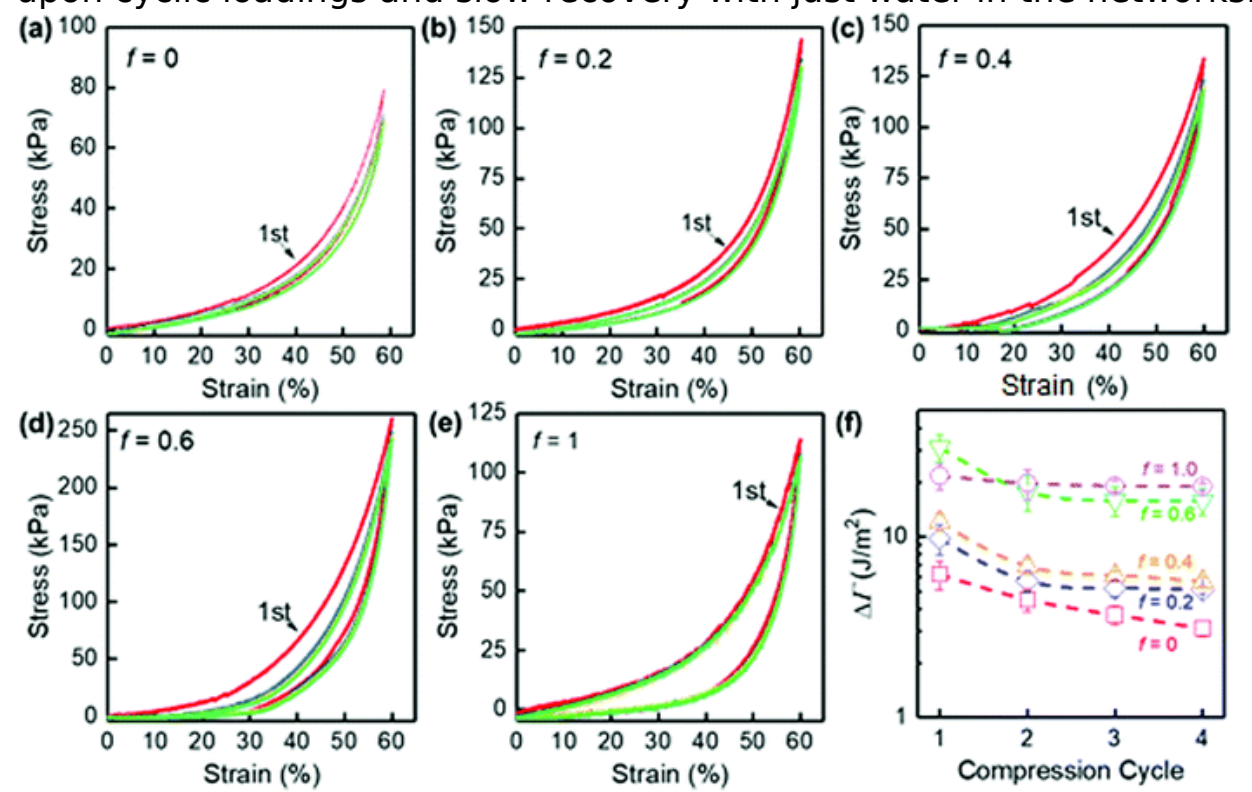

Fig. 4 (a-e) Representative cyclic loading-unloading curves of $\mathrm{FH}_{0}, \mathrm{FH}_{0.2}, \mathrm{FH}_{0.4}, \mathrm{FH}_{0.6}$ and $\mathrm{FH}_{1.0}$ gels. (f) The energy dissipation for $\mathrm{FH}_{0}, \mathrm{FH}_{0.2}, \mathrm{FH}_{0.4}, \mathrm{FH}_{0.6}$ and $\mathrm{FH}_{1.0}$ gels with increasing cycle numbers.

The $\Delta \Gamma$ of the $\mathrm{FH}$ hydro/organo-gels shows an obvious increase upon increasing the DMSO content (Fig. 4f). The $\Delta \Gamma$ increases from $9.8 \mathrm{~J} \mathrm{~m}^{-2}$ for the $\mathrm{FH}_{0.2}$ gel to $12.1 \mathrm{~J} \mathrm{~m}^{-2}$ for the $\mathrm{FH}_{0.4}$ gel for the first cycle. Subsequently, the $\Delta \Gamma$ shows a maximum value of $31.2 \mathrm{~J}$ $\mathrm{m}^{-2}$ for the $\mathrm{FH}_{0.6} \mathrm{gel}$ and then decreases to $17.8 \mathrm{~J} \mathrm{~m}^{-2}$ after the second cycle.

Interestingly, these $\mathrm{FH}_{0.2 \sim 1.0}$ gels maintain slow decay in comparison to the $\mathrm{FH}_{0}$ hydrogels after experiencing the first cycle. In particular, the loops of the $\mathrm{FH}_{1.0}$ organogel almost overlap with each other and the $\Delta \Gamma$ remains at a constant value of about $19 \mathrm{~J} \mathrm{~m}^{-2}$ after conducting the third cycles of loading-unloading (Fig. 4e and f). These results further confirm that the formed MeHA crystallite structures and the micelles within the gel can enable occurrence of large deformations, dislocations and microcracks in the water/DMSO binary solvent to resist compressive loading and dissipate energy. On the other hand, a previous study has demonstrated that insufficient lubrication of solvent in gel networks can bear shear force, which can improve the resistance against deformation. ${ }^{35}$ Here, the water/DMSO binary solvent causes dehydration of polymers upon increasing the DMSO content because DMSO does not lubricate the hydrophilic MeHA network. Therefore, such an insufficient lubrication effect induced by increasing the DMSO content in the binary 
solvent also contributed to the energy dissipation of the gel network. Moreover, it is fully different from our previous findings in the F127DA-micelle crosslinked PAAm gel where the $\Delta \Gamma$ decayed rapidly. It showed serious structural damage upon cyclic loadings and a slow recovery in the presence of DMSO within the networks. $\frac{31}{1}$ Therefore, the hydrogenbonds from MeHA endow the $\mathrm{FH}_{1.0}$ organogel with anti-damage and rapid self-recovery after loading-unloading tests.

\section{Conclusions}

A F127DA micelle-crosslinked hyaluronate (FH) hydro/organo-gel with controllable swelling and high mechanical performance was developed based on the DMSO/ $\mathrm{H}_{2} \mathrm{O}$ binary solvent strategy. In situ wide-angle X-ray diffraction and field emission scanning electron microscopy demonstrate that the DMSO induces a typical crystallite phase structure in $\mathrm{FH}$ gels. Although these $\mathrm{FH}$ gels are $\mathrm{DMSO} / \mathrm{H}_{2} \mathrm{O}$-philic according to contact angle measurement, their wettability and swelling ratios were strongly dependent on the dehydration effect due to the strong hydrogen-bonding interaction between DMSO and $\mathrm{H}_{2} \mathrm{O}$. The original soft FH hydrogel with a high swelling degree gradually became stiff with a decreased swelling degree as the DMSO contents in binary solvents increased. In particular, the $\mathrm{FH}$ gel with around $60-80 \%$ of DMSO showed the minimum swelling ratio and maximum compression strain, strength, modulus and toughness. We envision that such nanomicelle hydro/organo-gel with controllable mechanical properties is promising in the field of cryopreservation gels.

\section{Conflicts of interest}

The authors declare that there is no conflict of interests regarding the publication of this paper.

\section{Acknowledgements}

This work was supported by the National Natural Science Foundation of China [51803227, and 51773167], the Natural Science Foundation of Zhejiang Province [LY17E030011 and LQ19E030010], the S\&T Innovation 2025 Major Special Program of Ningbo [2019B10063 
and 2018B10040] and the CAS President's International Fellowship for Visiting Scientists [2019VBA0016].

\section{References}

1 M. Y. Kwon, C. Wang, J. H. Galarraga, E. Pure', L. Han and J. A. Burdick, Biomaterials, 2019, 222, 119451.

2 L. Lapc`ı`k, L. Lapc`ı’k, S. D. Smedt, J. Demeester and P. Chabreček, Chem. Rev., 1998, 98(8), 26632684.

3 H. D. Lu, D. E. Soranno, C. B. Rodell, I. L. Kim and J. A. Burdick, Adv. Healthcare Mater., 2013, 2, 1028 1036.

4 C. B. Rodell, J. W. MacArthur Jr., S. M. Dorsey, R. J. Wade, L. L. Wang, Y. J. Woo and J. A. Burdick, Adv. Funct. Mater., 2015, 25, 636-644.

5 C. B. Rodell, N. N. Dusaj, C. B. Highley and J. A. Burdick, Adv. Mater., 2016, 28(38), 8419-8424.

6 H. Zhang, P. G. Ren, Y. L. Jin and F. Ren, Mater. Lett., 2019, 243, 112-115.

7 P. G. Ren, H. Zhang, Z. Dai, F. Ren, Y. D. Wu, R. X. Hou, Y. B. Zhou and J. Fu, J. Mater. Chem. B, 2019, 7, 5490-5501.

8 X. H. Wang and H. R. Xu, Cryobiology, 2010, 61(3), 345-351.

9 G. Zhao, X. L. Liu, K. X. Zhu and X. M. He, Adv. Healthcare Mater., 2017, 6(23), 1770117.

10 E. G. Popa, M. T. Rodrigues, D. F. Coutinho, M. B. Oliveira, J. F. Mano, R. L. Reisab and M. E. Gomes, Soft Matter, 2013, 9, 875-885.

11 M. C. Phelan, Current Protocols in Cell Biology, John Wiley \& Sons, Inc., 2001.

12 K. Kubo and Y. Kuroyanagi, Artif. Organs, 2004, 28, 182-188.

13 J. Yang, N. Cai, H. Zhai, J. Zhang, Y. Zhu and L. Zhang, Sci. Rep., 2016, 6, 37458.

14 D. Zhou, F. Chen, S. Handschuh-Wang, T. Gan, X. Zhou and X. Zhou, ChemPhysChem, 2019, 20, 21392154.

15 H. Guo, T. Nakajima, D. Hourdet, A. Marcellan, C. Creton, W. Hong, T. Kurokawa and J. P. Gong, Adv. Mater., 2019, 31, 1900702.

16 G. K. Tummala, I. Bachi and A. Mihranyan, J. Appl. Polym. Sci., 2019, 136, 47044.

17 C. Fang, K. Yang, Q. Zhou, K. Peng and H. J. Yang, RSC Adv., 2018, 8, 35094-35101.

18 H. Gao, Z. Zhao, Y. Cai, J. Zhou, W. Hua, L. Chen, L. Wang, J. Zhang, D. Han, M. Liu and L. Jiang, Nat. Commun., 2017, 8, 15911.

19 J. Song, S. Chen, L. Sun, Y. Guo, L. Zhang, S. Wang, H. Xuan, Q. Guan and Z. You, Adv. Mater., 2020, 32, 1906994.

20 F. Heatley and J. E. Scott, Biochem. J., 1988, 254, 489-493. 
21 K. M. Liu, Y. B. Li, Y. Zuo, F. L. Xu, X. J. Wang and W. H. Yang, J. Funct. Mater., 2008, 39, 994-997.

22 R. M. Tarkka, I. H. Um, H. Q. Xie, A. P. Chatrouse, F. Terrier, S. Hoz and E. Buncel, J. Phys. Org. Chem., $1998,11,847-852$.

23 S. Ouyang, N. Wu, J. Liu, C. Sun, Z. Li and S. Gao, Chin. Phys., 2010, 19, 123101.

24 B. Kirchner and M. Reiher, J. Am. Chem. Soc., 2002, 124, 6206-6215.

25 X. Wang, Y. Zhang, L. Zhang and Y. Ding, J. Phys. Chem. B, 2009, 113, 9915-9923.

26 Y. Lei, H. Li and S. Han, Chem. Phys. Lett., 2003, 380, 542-548.

27 A. M. Schrader, S. H. Donaldson, J. Song, C. Y. Cheng, D. W. Lee, S. Han and J. N. Israelachvili, Proc. Natl. Acad. Sci. U. S. A., 2015, 112, 10708-10713.

28 H. Lin, J. Liu, K. Zhang, Y. Fan and X. Zhang, Carbohydr. Polym., 2015, 123, 381-389.

29 Polymeric Drugs and Drug Delivery Systems, ed. R. M. Ottenbrite and S. W. Kim, CRC Press, 2019, ch. 12.

30 D. Xu, T. Xu, G. Gao, Y. Xiao, Z. Wang, J. Chen, Y. Zhou, R. Wang, J. Yin and J. Fu, J. Polym. Sci., Part B: Polym. Phys., 2019, 57, 473-483.

31 B. Li, L. Zhang, Z. Zhang, R. Gao, H. Li, Z. Dong, Q. Wang, Q. Zhou and Y. Wang, RSC Adv., 2018, 8, 1693-1699.

32 W. Li, Y. Hu, L. Shi, X. Zhang, L. Xiong, W. Zhang and I. Ullah, J. Biomater. Sci., Polym. Ed., 2018, 29, 1155-1167.

33 S. Shaikh, D. Ray, V. K. Aswal and R. K. Sharma, J. Surfactants Deterg., 2017, 20, 695-706.

34 Y. L. Chang, C. Y. Hsieh, C. Y. Yeh and F. H. Lin, Polymers, 2019, 11, 1454.

35 J. C. Lei, Z. D. Zhou and Z. S. Liu, Polymers, 2019, 11, 1845.

\section{Footnote}

† Electronic supplementary information (ESI) available. See DOI: 10.1039/d0sm01099e 